\title{
The influence of the $W W O X$ gene on the regulation of biological processes during endometrial carcinogenesis
}

\author{
E. PŁUCIENNIK ${ }^{1}$, M. NOWAKOWSKA ${ }^{1}$, M. GAŁDYSZYŃSKA ${ }^{2}$, M. POPĘDA ${ }^{3}$ and A.K. BEDNAREK ${ }^{1}$ \\ Departments of ${ }^{1}$ Molecular Carcinogenesis and ${ }^{2}$ Comparative Endocrinology, ${ }^{3}$ Faculty of Biomedical Sciences \\ and Postgraduate Education, Medical University of Lodz, 90-752 Lodz, Poland
}

Received October 16, 2015; Accepted January 11, 2016

DOI: $10.3892 / \mathrm{ijmm} .2016 .2469$

\begin{abstract}
The purpose of the present study was to investigate the role of WW domain containing oxidoreductase (WWOX) downregulation in biological cancer-related processes in normal (non-malignant) and cancer endometrial cell lines. We created an in vitro model using the normal endometrial cell line, THESC, and 2 endometrial cancer cell lines with varying degrees of differentiation, the Ishikawa (well-differentiated) and the MFE296 (moderately differentiated) cells, in which the WWOX tumor suppressor gene was silenced using Gipz lentiviral shRNA. In this model, we examined the changes in invasiveness via biological assays, such as zymography, migration through a basement membrane, the adhesion of cells to extracellular matrix proteins, anchorage-independent growth and colony formation assay. We also evaluated the correlation between the mRNA expression of the $W W O X$ gene and genes involved in the processes of carcinogenesis, namely catenin beta-1 (CTNNBI) and zinc finger E-box binding homeobox 1 (ZEBI) (gene transcription), cadherin 1 (CDH1) and ezrin (EZR) (cell adhesion), vimentin (VIM) (structural proteins), as well as phosphatase and tensin homolog $(P T E N)$ (tumor suppression) and secreted protein, acidic, cysteine-rich (osteonectin) (SPARC) (SPARC) (cell growth regulation) by RT-qPCR. Downregulation of the WWOX gene in the moderately differentiated MFE296 cell line caused decreased migratory capacity, and a reduction of matrix metalloproteinase-2 (MMP-2) activity. However, these cells grew in semisolid medium and exhibited higher expression of $C D H 1$ and EZR (cell adhesion) and secreted protein, acidic, cysteine-rich (osteonectin) (SPARC) (cell growth regulation). Moreover, in the well-differentiated endometrial cancer (Ishikawa) cell line, WWOX gene silencing resulted in an increased ability of the cells to proliferate indefinitely. Additionally, $W W O X$ regulated changes in adhesion potential in both the normal and cancer cell lines. Our results suggest that
\end{abstract}

Correspondence to: Dr Elżbieta Płuciennik, Department of Molecular Carcinogenesis, Medical University of Lodz, Zeligowskiego 7/9, 90-752 Lodz, Poland

E-mail: elzbieta.pluciennik@umed.lodz.pl

Key words: carcinogenesis, endometrium, invasiveness, $W W O X$ the WWOX tumor suppressor gene modulated the processes of cell motility, cell adhesion, gene expression and remodeling in endometrial cell lines.

\section{Introduction}

Endometrial cancer (EC) is the most frequently diagnosed malignancy of the female reproductive tract and the fourth most common malignancy in women in Poland, after breast and lung cancer. In 2012 the incidence of endometrial cancer in Polish women was estimated at 5,426 of new cases and 1,162 of deaths (1).

In 1983, Bokhman et al (2) proposed a dualistic model of endometrial carcinogenesis based on clinical and prognostic factors. Type I, estrogen-dependent endometrioid carcinomas (EEC) comprises the sporadic cancers with a low grade and favorable prognosis $(3,4)$. The precursor of this group of malignancies is atypical hyperplasia of the endometrium and progressive mutation/methylation in mismatch repair genes [MutL homolog 1 (MLH1), MutS homolog 2 (MSH2) and MutS homolog 6 (MSH6)], and the oncogenes Kirsten rat sarcoma viral oncogene homolog $(K R A S)$ and catenin beta-1 $(C T N N B 1)$. Inactivation of phosphatase and tensin homolog (PTEN) and loss of expression of the cadherin $1(\mathrm{CDHI})$ gene are also typical for this type of neoplastic lesion $(5,6)$.

Type II, non-endometrioid endometrial carcinomas (NEECs), are on the contrary not associated with oestrogen stimulation. These high-grade tumors progress from the atrophic endometrium and are typified by serous papillary or clear-cell morphology, an aggressive clinical course and poor prognosis, resulting from their high potential for deep myometrial invasion and lymphatic spread $(3,7)$. NEECs are characterized by mutations of the tumor protein P53 (TP53) tumor suppressor gene, leading to accumulation of non-functional $\mathrm{p} 53$ protein and thus deregulation of cell cycle control $(4,7)$. As for oncogenic alterations, intensification of oncogenic signals and subsequent excessive cell growth and differentiation due to overexpression of human epidermal growth factor receptor 2 (HER2)/neu has been reported in type II EC (4). Moreover, NEECs have been found to present significant genomic instability at a chromosomal level, which is caused by telomere shortening and results in a high level of aneuploidy, regardless of the active response of the MMR system $(6,7)$. 
The WWOX tumor suppressor gene, encoding the WW domain containing oxidoreductase, is also known as FOR, fragile site FRA16D oxidoreductase. The WWOX gene is localized in region 16q23.3-24.1, also referred to as common fragile site FRA16D. The WWOX protein contains two N-terminal WW-domains, and one central SDR domain. The first WW domain (WW1) of the WWOX protein possesses the ability to associate with proteins containing a specific proline-rich motif, PPXY. Since WWOX has been found to generate such interactions with molecules involved in transcriptional regulation or signal transduction e.g. via SMAD3 (8), RUNX2 (9), c-Jun (10), p73 (11), AP-2 $\alpha / \gamma(12)$, ERBB4 $(13,14)$, and HIF1 $\alpha$ (15), it is thus thought to participate in the process of carcinogenesis (16). Alterations in the WWOX tumor suppressor gene have been observed, in cases of cancer, of many hormone-regulated tissues, including those of the breast, ovary, prostate and testis (17-20). It has been shown that loss of WWOX expression is correlated with unfavorable factors, such as grade, stage, lymph node metastasis $(6,19,21)$ and a lower degree of cancer cell differentiation (20). Additionally, our previous analysis conducted on normal and EC samples revealed a decrease in WWOX protein level in tissues with acquired cancer phenotype. We have also observed a tendency of $W W O X$ gene mRNA to decrease between grade 1 and 2, FIGO stage 1 and 2, and thus it is correlated with deeper myometrial invasion (22). Much data from previous studies demonstrate WWOX protein participation and regulation of various processes involved in tumor development and progression (23-27). One of these processes is epithelial-mesenchymal transition (EMT), Yan and Sun indicated that the WWOX gene may reverse the EMT in ovarian cancer stem cells by regulating the expression of two EMT factors, Elf5 and Snail (28). In our previous study we also observed the influence which WWOX exerted on the EMT process via modulation of cell motility and suppression of the main mezenchymal marker, i.e., vimentin (VIM) (29).

The aim of the present study was to analyze the impact of differential WWOX expression on biological cancer-related processes in endometrial cell lines, both non-cancerous and cancerous, which varied also in cellular differentiation status. Accordingly, we silenced $W W O X$ expression in the human normal endometrial stromal cell line THESC and two EC cell lines with different statuses of differentiation: Ishikawa (grade 1; well-differentiated, expressing both estrogen and progesterone receptors), and MFE296 (grade 2; moderately differentiated, lacking the expression of estrogen receptors but susceptible to androgen-induced inhibition of proliferation).

\section{Materials and methods}

Cell culture. MFE296, THESC and Ishikawa cell lines were obtained from the Leibniz Institut DSMZ, German Collection of Microorganisms and Cell Cultures GmbH (Braunschweig, Germany), American Type Culture Collection (ATCC, Manassas, VA, USA) and Sigma-Aldrich (Poznań, Poland), respectively. The MFE296 cells were cultured in minimum essential medium supplemented with $10 \%$ fetal bovine serum (FBS), $2 \mathrm{mM}$ L-glutamine, $2 \mathrm{mM}$ sodium pyruvate and $1 \% \mathrm{PSN}$ antibiotic mixture (penicillin $50 \mu \mathrm{g} / \mathrm{ml}$, streptomycin $50 \mu \mathrm{g} / \mathrm{ml}$, neomycin $100 \mu \mathrm{g} / \mathrm{ml}$; Life Technologies, Carlsbad, CA, USA). The Ishikawa cells were cultured in minimum essential medium containing $1 \%$ non-essential amino acids and supplemented with 5\% FBS, $2 \mathrm{mM}$ L-glutamine, $2 \mathrm{mM}$ sodium pyruvate and $1 \%$ PSN antibiotic mixture. The THESC cell line was cultured in DMEMF-12 medium without phenol red with $3.1 \mathrm{~g} / \mathrm{l}$ glucose and $1 \mathrm{mM}$ sodium pyruvate supplemented with $1.5 \mathrm{~g} / 1$ sodium bicarbonate, $1 \%$ ITS + Premix (cat. no. 354352; BD Biosciences, Franklin Lakes, NJ, USA), $500 \mathrm{ng} / \mathrm{ml}$ puromycin, $10 \%$ and charcoal/dextran treated FBS (cat. no. SH30068.03; HyClone, Logan, UT, USA).

shRNA-mediated silencing of the WWOX gene. GIPZ Lentiviral $^{\mathrm{TM}}$ shRNA technology (Thermo Fisher Scientific, Waltham, MA, USA) was used to modulate WWOX expression in all cell lines. A mix of commercially available lentiviral particles (V2LHS_115633, V2LHS_255229 and V2LHS_411864; Thermo Fisher Scientific), comprising shRNA complementary to the sequence of WWOX mRNA, was introduced into serum-starved cells according to the manufacturers' instructions (MOI of 5). Polybrene (5 $\mu \mathrm{g} / \mathrm{ml}$; Sigma-Aldrich) was added to the transduction medium to increase efficiency of the process. Cells transduced with non-silencing lentiviral shRNA vector (Thermo Fisher Scientific), containing an shRNA sequence with no homology to known mammalian genes, served as a negative control. Selection of the transduced cells was based on resistance to puromycin (1 $\mu \mathrm{g} / \mathrm{ml}$; Sigma Aldrich). Additionally, the lentiviral vector which was used contained GFP protein, and observation, using a fluorescence microscope (Life Technologies), of TurboGFP expression was used as a control method for transduction.

Protein extraction and western blot analysis. Protein samples were obtained using RIPA protein extraction buffer supplemented with protease, phosphatase inhibitor coctail and PMSF (Sigma-Aldrich). Protein concentration was measured using the Bradford method (Bio-Rad Laboratories, Warsaw, Poland), and samples were subsequently separated in $10 \%$ SDS-PAGE gel electrophoresis and transferred to PVDF membranes (SigmaAldrich). The membranes were blocked in 5\% non-fat milk in TBST for $1 \mathrm{~h}$ at room temperature and then incubated with a primary antibody to goat anti-human WWOX, 1:100 (sc:20529; Santa Cruz Biotechnology Inc., Santa Cruz, CA, USA) for $19 \mathrm{~h}$ at $4^{\circ} \mathrm{C}$. Subsequently, the membranes were washed three times with TBST buffer and incubated with secondary antibodies conjugated with alkaline phosphatase (Sigma-Aldrich) for $1 \mathrm{~h}$. Membranes washed with TBST were then developed using Novex ${ }^{\circledR}$ AP Chromogenic Substrate (Invitrogen, Carlsbad, CA, USA). Glyceraldehyde-3-phosphate dehydrogenase (GAPDH) at a dilution of 1:1,000 (sc-59540; Santa Cruz Biotechnology, Inc.) served as the internal control.

Cell-culture assays. Due to the limited number of divisions, the normal endometrial cell line THESC underwent only an adhesion assay after silencing. All biological tests were performed in a minimum of three replicates.

Adhesion assay. Adhesiveness of both variants (with and without WWOX silencing) of MFE-296, Ishikawa and THESC cells was evaluated by means of a plate coated with fibronectin, collagen type I and IV, laminin type I and fibrinogen (CytoSelect $^{\mathrm{TM}}$ 48-well cell adhesion assay kit; Cell Biolabs, Inc., San Diego, CA, 
USA) according to the manufacturer's instructions. BSA-coated wells served as the negative controls. Cells were seeded on the plate $\left(1.5 \times 10^{5} /\right.$ well) and incubated for $90 \mathrm{~min}$ at $37^{\circ} \mathrm{C}$ in $5 \% \mathrm{CO}_{2}$ to enable interaction with the extracellular matrix components. Cellular adhesion was quantified spectrophotometrically at 560 nm (EL808; BioTek, Bedfordshire, UK).

Integrin expression test. The $\alpha / \beta$ integrin-mediated cell adhesion array combo kit (Chemicon, Temecula, CA, USA) was used to analyze the adhesion of MFE-296 and Ishikawa cells to anti-integrin antibodies, according to the manufacturer's instructions. Both variants of cell lines were seeded on a plate $\left(1.5 \times 10^{5}\right.$ cells/well) and incubated for $2 \mathrm{~h}$ at $37^{\circ} \mathrm{C}$ in an atmosphere with $5 \% \mathrm{CO}_{2}$. Absorbance was measured at $560 \mathrm{~nm}$ with a BioTek plate reader.

Invasion assay. The CytoSelect ${ }^{\mathrm{TM}}$ Cell Invasion Assay kit (Cell Biolabs, San Diego, CA, USA) was used to assess the invasiveness of MFE-296 and Ishikawa cell lines according to the manufacturer's instructions. Complete culture medium was added to wells, and the cells suspended in starving medium were seeded $\left(3 \times 10^{5} /\right.$ well) onto the inner compartment of each insert. The plate was incubated for $48 \mathrm{~h}$ at $37^{\circ} \mathrm{C}$ in $5 \% \mathrm{CO}_{2}$. The cells attached to the bottom of the membrane were stained with $0.005 \%$ crystal violet, and the number of cells was assessed spectrophotometrically at $560 \mathrm{~nm}$ (EL808; BioTek). The test was performed in triplicate for each cell variant.

Soft agar assay. Anchorage-independent proliferation potential of both variants of MFE-296/Ishikawa cells was estimated using a soft agar colony formation assay. A 2-ml layer of $0.9 \%$ agar in complete culture medium was poured into a 6 -well plate. Subsequently, the cells of each variant were suspended in $0.3 \%$ agar medium and inoculated $\left(1 \times 10^{4} /\right.$ well) on the top of the base layer. The plate was then incubated (for 14 days, at $37^{\circ} \mathrm{C}$, in an atmosphere with $5 \% \mathrm{CO}_{2}$ ), allowing for the observation of cell growth and colony formation in the semisolid medium. After incubation, the colonies were stained with $0.005 \%$ crystal violet ( $15 \mathrm{~min}, \mathrm{RT}$ ) and counted using ImageJ software (National Institutes of Health, Bethesda, MD, USA; http://rsb.info.nih.gov/ij/). The test was performed in triplicate for each cell variant.

Clonogenic assay. The MFE296 and Ishikawa cells of each variant were seeded $\left(5 \times 10^{2} /\right.$ well) onto a 6 -well plate in complete culture medium. After incubation (for 10 days, at $37^{\circ} \mathrm{C}$, in an atmosphere with $5 \% \mathrm{CO}_{2}$ ), the cells were fixed with $4 \%$ paraformaldehyde solution in phosphate-buffered saline (PBS). Colonies were stained with $0.005 \%$ crystal violet $(15 \mathrm{~min}$, at room temperature) and counted using ImageJ software. The test was performed in triplicate for each cell variant.

Zymography. Cells were seeded on 6-well plates (1.5x10\% $/$ well), cultured to $80 \%$ confluence and serum-starved $24 \mathrm{~h}$ prior to medium collection. Protein concentration in the obtained cell culture supernatants was measured using a Qubit protein assay and Qubit 2.0 fluorometer (both from Invitrogen Life Technologies). Protein extracts $(2 \mu \mathrm{g})$ were separated in $10 \%$ SDS-PAGE gel, supplemented with gelatin $(2 \mathrm{mg} / \mathrm{ml})$. After electrophoresis, the gel was washed with Triton X-100 (2x30 min) and incubated in a developing buffer (0.5 M Tris- $\mathrm{HCl}, 2 \mathrm{M} \mathrm{NaCl}, 50 \mathrm{mM} \mathrm{CaCl}_{2}$, $\mathrm{pH} 7.5$ ) overnight at $37^{\circ} \mathrm{C}$. Subsequently, the gel was incubated alternately with Coomassie Brilliant Blue R-250 staining and destaining solution (methanol:acetic acid:water, 3:1:6) until clear bands were observed over the dark background. Gelatinolytic activity of enzymes in samples appeared in the form of clear bands and was further evaluated by means of ImageJ software based on the band area.

$R T-q P C R$. Total RNA was extracted from cells using TRIzol reagent (Invitrogen, Carlsbad, CA, USA). cDNA synthesis was performed as previously described (22). Gene expression was analyzed using LightCycler 480 (Roche Diagnostics, Warsaw, Poland), with SYBR ${ }^{\circledR}$-Green I and a qPCR Core kit for SYBR ${ }^{\circledR}$ Green I (Eurogentec, Southampton, UK). Expression levels of studied genes were normalized to the mean expression of reference genes ribosomal protein S17 (RPS17), ribosomal protein, large, P0 (RPLP0) and H3 histone, family 3A (H3F3A)]. Primer sequences, PCR reaction conditions and length of the obtained products are listed in Table I. Each reaction was performed in duplicate and Universal Human Reference RNA (Stratagene, Perlan Technology, Warszaw, Poland) was used as the calibrator. Gene expression levels were calculated according to Roche algorithm (30).

Statistical analysis. Statistical analysis of the data was performed using Statistica 8.0 (StatSoft). The Aspin-Welsch test was applied to determine the differences between data obtained for both cell variants in cell-culture assays. A p-value $<0.05$ was considered to indicate a statistically significant difference.

\section{Results}

Successful transduction was determined by positive rates of TurboGFP fluorescence observed in both variants (those which received WWOX silencing and those which did not) of the cell lines.

Silencing of the $W W O X$ gene was confirmed also at protein level, by western blot analysis. The WWOX protein was suppressed by $66.9 \%$ in THESC ( $<<0.001), 59.2 \%$ in Ishikawa $(\mathrm{p}=0.029)$ and 56\% in MFE296 (p=0.014) cell lines (Fig. 1).

As a result of $W W O X$ gene silencing, we observed changes in the behaviour of the cell lines, but the observed changes did not always follow the same direction.

The invasion assay, which was performed with basal membrane-coated inserts, demonstrated that the silencing of WWOX gene expression in MFE296 cells caused a moderate (by $27.6 \%)$ decrease of invasive ability $(\mathrm{p}=0.036)$ in comparison to the control cells. By contrast, in the Ishikawa (ISH) cell line, this resulted in insignificant modulation of their invasive potential (Fig. 2).

Moreover, the amount of active matrix metalloproteinase-2 (MMP-2) in MFE296/shWWOX was demonstrated to be significantly reduced (arbitrary units of enzyme: $15185 \pm 154.7$ vs. $9790 \pm 420.2$; downregulation approximately $36 \%, \mathrm{p}=0.002$ ) when compared to control cells.

We also tested anchorage-independent growth. Therefore, we used soft agar and colony formation assays, which were conducted in order to assess whether WWOX silencing affected the clonogenicity of EC cells as well as their ability to grow 
Table I. RT-qPCR primer sequences.

\begin{tabular}{|c|c|c|c|c|}
\hline Gene & Primer sequences & Product (bp) & Annealing $\left({ }^{\circ} \mathrm{C}\right)$ & Reading $\left({ }^{\circ} \mathrm{C}\right)$ \\
\hline \multicolumn{5}{|c|}{ Reference genes } \\
\hline \multirow[t]{2}{*}{ RPS17 } & 5'-AAGCGCGTGTGCGAGGAGATCG-3' & & & \\
\hline & 5'-TCGCTTCATCAGATGCGTGACATAACCTG-3' & 87 & 64 & 72 \\
\hline \multirow[t]{2}{*}{$H 3 F 3 A$} & 5'-AGGACTTTAAAAGATCTGCGCTTCCAGAG-3' & & & \\
\hline & 5'-ACCAGATAGGCCTCACTTGCCTCCTGC-3' & 76 & 65 & 72 \\
\hline \multirow[t]{2}{*}{$R P L P O$} & 5'-ACGGATTACACCTTCCCACTTGCTAAAAGGTC-3' & & & \\
\hline & 5'-AGCCACAAAGGCAGATGGATCAGCCAAG-3' & 69 & 65 & 72 \\
\hline \multicolumn{5}{|c|}{ Analyzed genes } \\
\hline \multirow[t]{2}{*}{$\mathrm{CDH} 1$} & 5'-TCCCCCGGTATCTTCCCCGCCCTG-3' & & & \\
\hline & 5'-AGTTCAGGGAGCTCAGACTAGCAGCTTCGG-3' & 168 & 63 & 82 \\
\hline \multirow[t]{2}{*}{$C T N N B 1$} & 5'-AAAATGGCAGTGCGTTTAG-3' & & & \\
\hline & 5'-TTTGAAGGCAGTCTGTCGTA-3' & 100 & 58 & 72 \\
\hline \multirow[t]{2}{*}{$Z E B 1$} & 5'-GGAAATCAGGATGAAAGACA-3' & & & \\
\hline & 5'-CACACAAATCACAAGCATAC-3' & 136 & 63 & 72 \\
\hline \multirow[t]{2}{*}{$V I M$} & 5'-AGCCGAAAACACCCTGCAAT-3' & & & \\
\hline & 5'-CGTTCAAGGTCAAGACGTC-3' & 72 & 58 & 72 \\
\hline \multirow[t]{2}{*}{$E Z R$} & 5'-CTCACCGTATGGCTGCACTG-3' & & & \\
\hline & 5'-СTTCATCCTCCTTGCGCCTC-3' & 153 & 55 & 72 \\
\hline \multirow[t]{2}{*}{ PTEN } & 5'-CGAACTGGTGTAATGATATGT-3' & & & \\
\hline & 5'-CATGAACTTGTCTTCCCGT-3' & 330 & 55 & 72 \\
\hline \multirow[t]{2}{*}{ SPARC } & 5'-TGGACTACATCGGGCCTTGCAAATACATC-3' & & & \\
\hline & 5'-TTCTTGAGCCAGTCCCGCATGCAG-3' & 91 & 65 & 72 \\
\hline
\end{tabular}

$C D H 1$, cadherin 1; EZR, ezrin; SPARC, secreted protein, acidic, cysteine-rich (osteonectin); CTNNB1, catenin beta-1; RPS17, ribosomal protein S17; RPLPO, ribosomal protein, large, P0; H3F3A, H3 histone, family 3A; ZEB1, zinc finger E-box binding homeobox 1; PTEN, phosphatase and tensin homolog; VIM, vimentin.

in suspension, which is the characteristic feature of malignant cancer cells. We noted that ectopic WWOX silencing resulted in an increased ability to form colonies for the variants with silenced WWOX expression in both cancerous cell lines examined. It is worth noting that MFE296 cells presented higher clonogenicity than the well-differentiated ISH cell line (MFE296/controlshRNA variant formed 5.5-times more colonies than the Ishikawa/control-shRNA variant). However, the increased ability to form colonies in suspension was more evident in Ishikawa cells than in MFE296 cells (by $68 \%, \mathrm{p}=0.03$ and by $50.5 \%$, $\mathrm{p}=0.11$, respectively) (Fig. 3). On the other hand, the soft agar assay demonstrated different effects on anchorage-independent proliferation after $W W O X$ silencing in the two EC cell lines. A substantial, yet not statistically significant, decrease of growth in semisolid medium was observed in Ishikawa cells $(43.4 \%$, $\mathrm{p}=0.09$ ), while a significant $27.7 \%$ increase was observed in the MFE296/shWWOX variant (p=0.019) (Fig. 4).

Subsequently, the adhesion to the extracellular matrix (ECM) and its response to $W W O X$ gene silencing was evaluated in the normal endometrial cell line and both cancer cell lines (Fig. 5).

The silencing of the WWOX gene in the THESC cell line caused a significant decrease in adhesion to four ECM proteins: fibronectin, collagen 1 , laminin 1 and fibrinogen $(\mathrm{p}<0.005)$.

The subsequent analysis of the adhesion assay revealed significant differences between the two EC cell lines. In
Ishikawa cells, silencing caused a $49 \%$ increase $(p=0.05)$ in fibronectin adhesion, and in MFE296 cells it resulted in a $37 \%$ increase in adhesiveness to fibrinogen $(\mathrm{p}=0.006)$.

To emphasize the effect that decreased $W W O X$ expression had on the regulation of adhesion properties, its influence on cell surface integrin expression and integrin-mediated cell adhesion was also assessed. Discordant results were observed for both cancer cell lines. In MFE296 cells, it resulted in >2-fold increase in the adhesion mediated by subunit $\alpha 3$ integrin (3.7-fold). On the other hand, in Ishikawa cells it resulted in decreased adhesion mediated by two $\alpha$ subunits of integrins (between 2.0- and 2.8-fold for integrin $\alpha 1$ and $\alpha 4$, respectively) (Fig. 6).

RT-qPCR was performed in order to evaluate the expression of genes involved in carcinogenesis-regulating processes: CTNNB1 and zinc finger E-box binding homeobox 1 (ZEB1) (gene transcription), $C D H 1$ and ezrin (EZR) (cell adhesion), VIM (structural proteins) as well as PTEN (tumor suppression) and secreted protein, acidic, cysteine-rich (osteonectin) $(S P A R C)$ (cell growth regulation). We noted that in both cell lines the silencing of the $W W O X$ tumor suppressor gene resulted in an increase ( $>2$ fold-change) in the expression of EZR. However, only in the MFE296 cell line was this association statistically significant $(\mathrm{p}=0.04)$. Only in MFE296 cells did it cause $>2$-fold increase in the expression of $C D H 1, E Z R$ and SPARC $(\mathrm{p}<0.05)$ (complete data shown in Table I). 

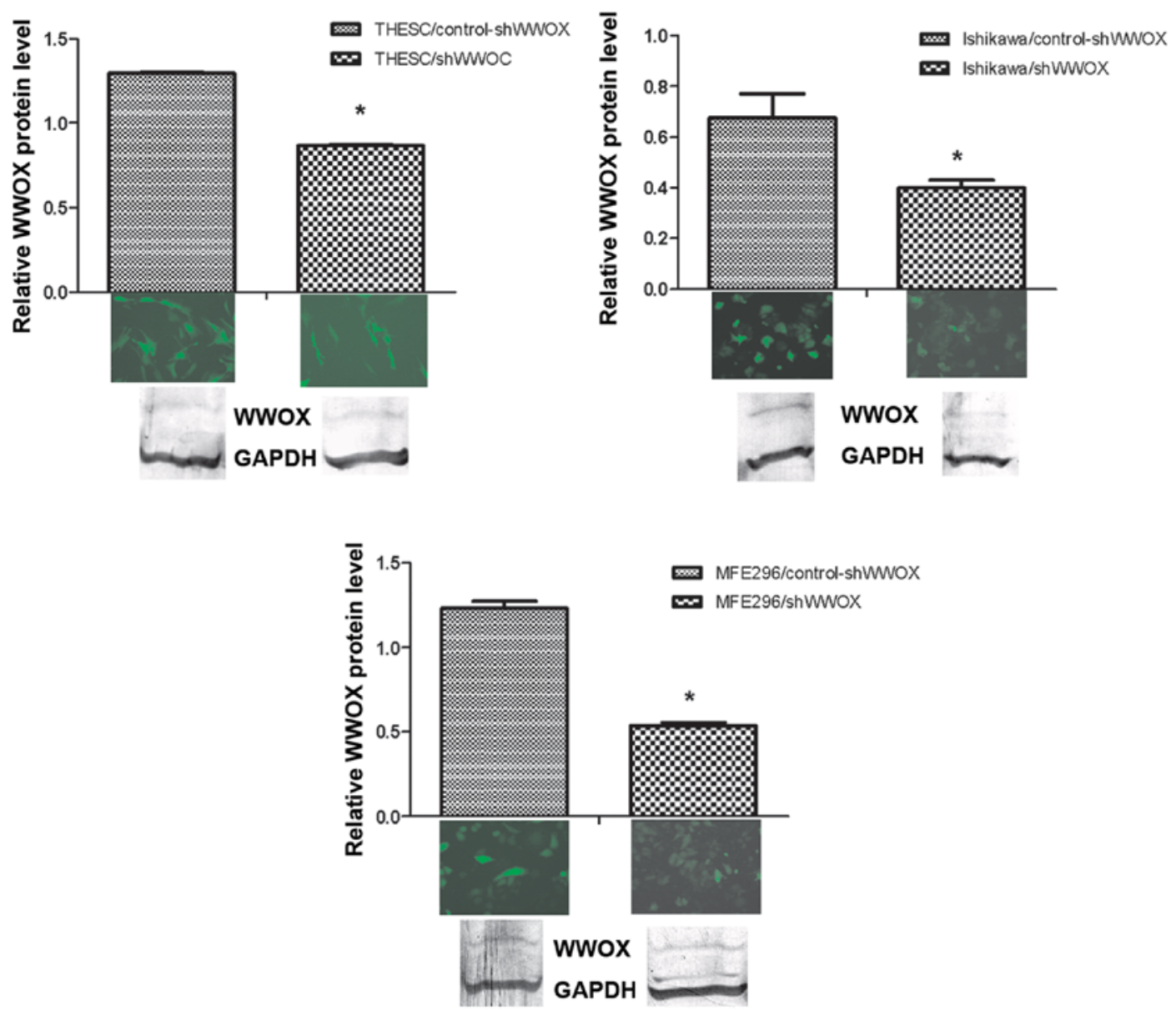

Figure 1. Confirmation of silencing of the WW domain containing oxidoreductase (WWOX) gene in three endometrial cell lines after transduction of shRNA on the protein level. Positive rates of TurboGFP fluorescence should be noted. The data are presented as the means $\pm \mathrm{SD} ;{ }^{*} \mathrm{p}<0.05$.
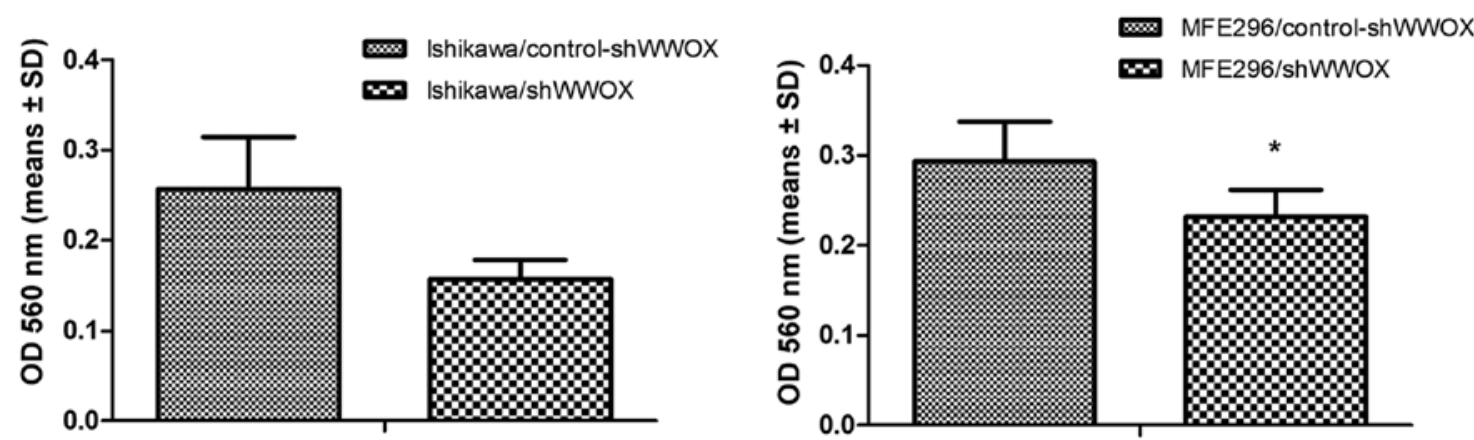

Figure 2. The effect of WW domain containing oxidoreductase (WWOX) silencing on invasion ability in Ishikawa and MFE296 cell lines. The data are presented as the means $\pm \mathrm{SD} ;{ }^{*} \mathrm{p}<0.05$.
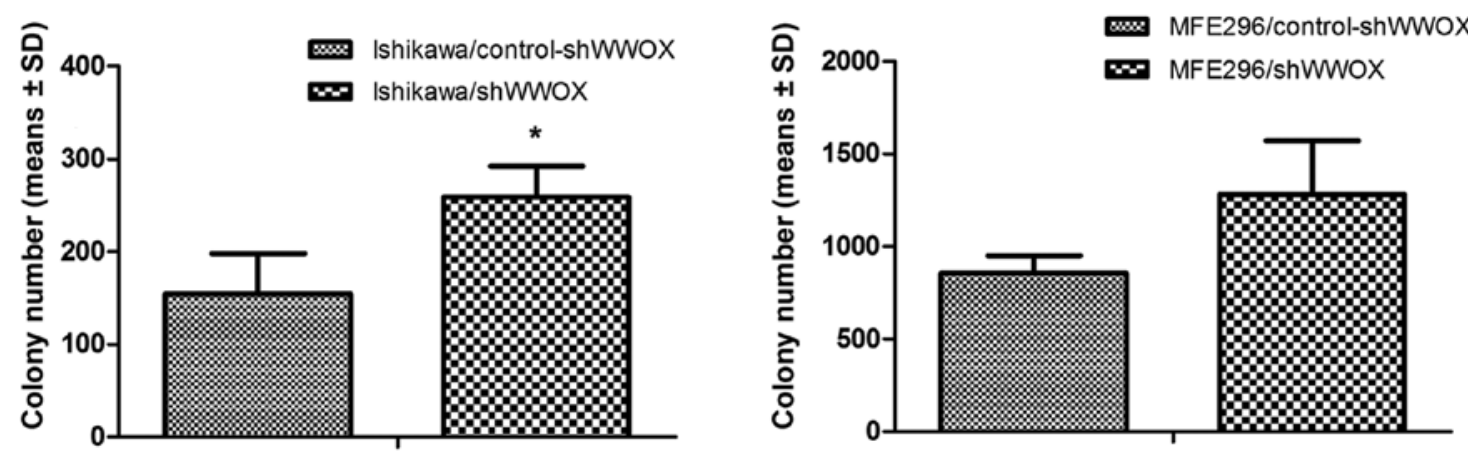

Figure 3. Colony formation assay of Ishikawa cells (shWWOX and control shWWOX) and MFE296 cells (shWWOX and control shWWOX). The data are presented as the means $\pm \mathrm{SD} ;{ }^{*} \mathrm{p}<0.05$. WWOX, WW domain containing oxidoreductase. 

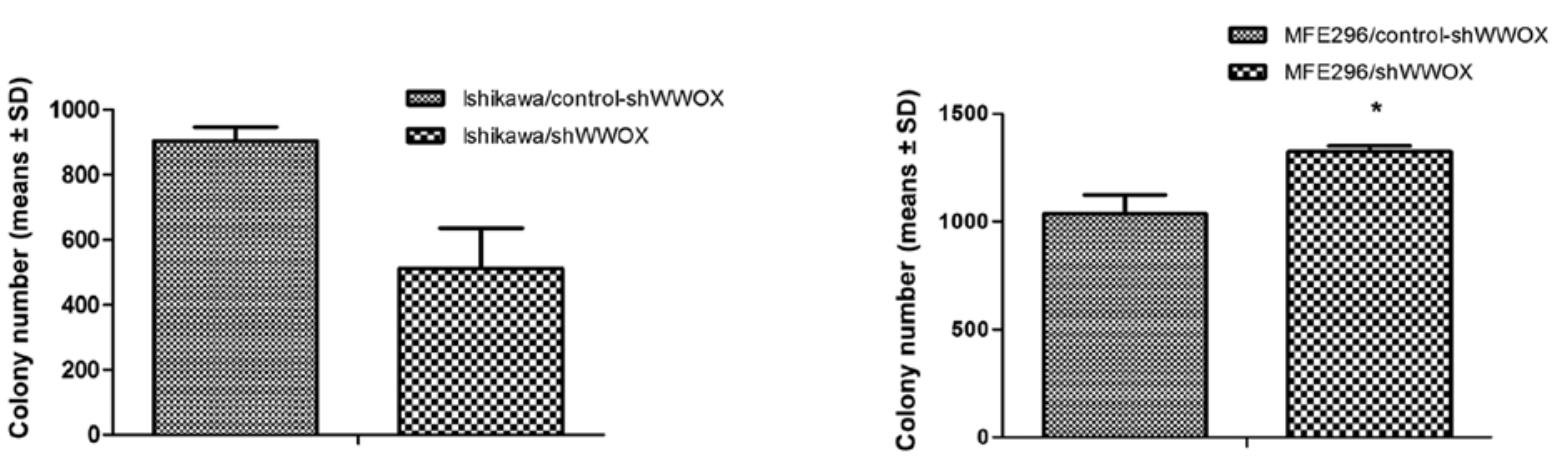

Figure 4. Ability to grow in soft agar of Ishikawa cells (shWWOX and control shWWOX) and MFE296 cells (shWWOX and control shWWOX). The data are presented as the means $\pm \mathrm{SD} ;{ }^{*} \mathrm{p}<0.05$. WWOX, WW domain containing oxidoreductase.
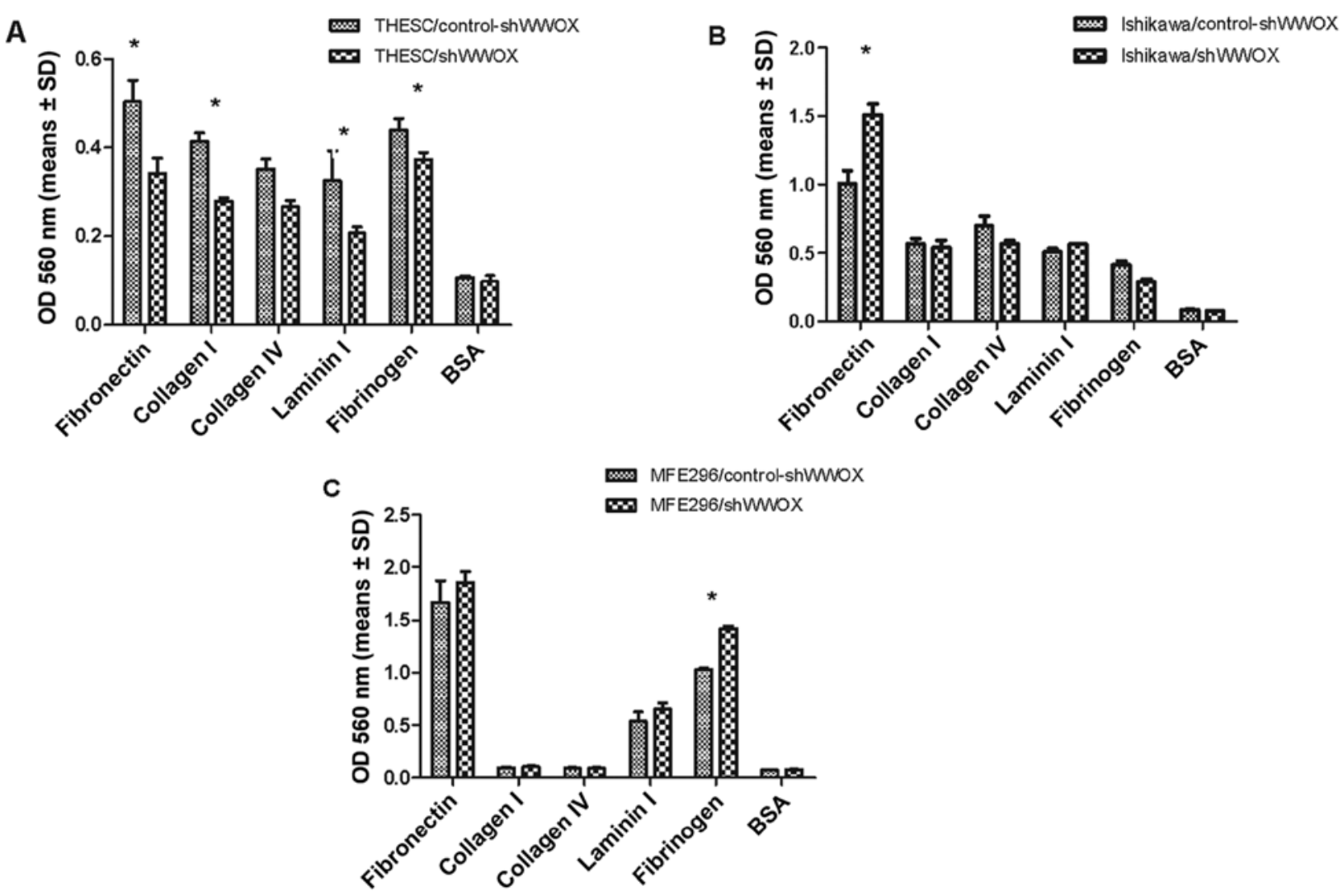

Figure 5. Extracellular matrix-mediated adhesion of (A) THESC cells (shWWOX and control shWWOX), (B) Ishikawa cells (shWWOX and control shWWOX) and (C) MFE296 cells (shWWOX and control shWWOX). The data are presented as the means \pm SD; ${ }^{*} p<0.05$. WWOX, WW domain containing oxidoreductase.

\section{$\alpha$ integrin adhesion profile}

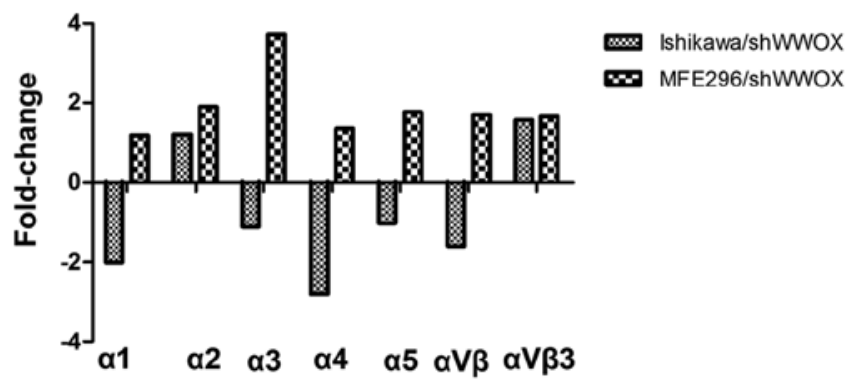

$\beta$ integrin adhesion profile

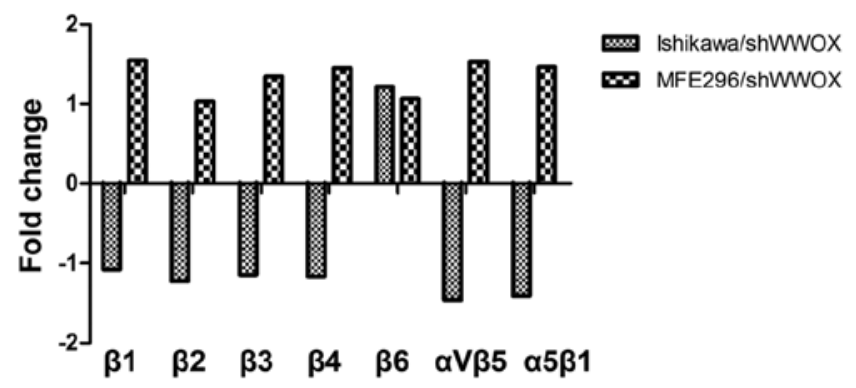

Figure 6. The fold change adhesion of $\alpha / \beta$ subunits of integrins after silencing WW domain containing oxidoreductase (WWOX) gene in Ishikawa and MFE296 cell lines. 
Table II. Changes in relative expression levels of cancer-related genes in MFE-296 and Ishikawa cell lines (with and without $W W O X$ silencing). The data are presented as the means $\pm \mathrm{SD}$.

\begin{tabular}{lccccccrr}
\hline Genes & ISH/shWWOX & $\begin{array}{c}\text { ISH/control- } \\
\text { shRNA }\end{array}$ & Fold change & p-value & $\begin{array}{c}\text { MFE296/ } \\
\text { shWWOX }\end{array}$ & $\begin{array}{c}\text { MFE296/control- } \\
\text { shRNA }\end{array}$ & Fold change & p-value \\
\hline CDH1 & $2.43 \pm 0.12$ & $2.32 \pm 0.14$ & 1.05 & $<0.05$ & $0.12 \pm 0.01$ & $0.05 \pm 0.01$ & 2.40 & $\mathbf{0 . 0 2}$ \\
CTNNB1 & $1.10 \pm 0.18$ & $0.62 \pm 0.06$ & 1.77 & $<0.05$ & $1.55 \pm 0.37$ & $0.39 \pm 0.06$ & -3.97 & $<0.05$ \\
ZEB1 & $0.63 \pm 0.01$ & $0.41 \pm 0.07$ & 1.54 & $<0.05$ & $0.53 \pm 0.04$ & $0.62 \pm 0.03$ & -0.85 & $<0.05$ \\
VIM & $0.0011 \pm 0.0001$ & $0.0008 \pm 0.0001$ & 1.38 & $<0.05$ & $0.33 \pm 0.03$ & $0.51 \pm 0.051$ & -0.65 & $<0.05$ \\
EZR & $2.74 \pm 0.02$ & $1.02 \pm 0.40$ & 2.69 & $<0.05$ & $2.03 \pm 0.09$ & $0.95 \pm 0.01$ & 2.14 & $\mathbf{0 . 0 4}$ \\
PTEN & $0.12 \pm 0.02$ & $0.14 \pm 0.01$ & -0.86 & $<0.05$ & $0.60 \pm 0.005$ & $0.43 \pm 0.20$ & 1.39 & $<0.05$ \\
SPARC & $0.0004 \pm 0.00001$ & $0.0003 \pm 0.00003$ & 1.33 & $<0.05$ & $0.15 \pm 0.01$ & $0.06 \pm 0.008$ & 2.50 & $\mathbf{0 . 0 3}$ \\
\hline
\end{tabular}

WWOX, WW domain containing oxidoreductase; ISH, Ishikawa; $C D H 1$, cadherin 1; EZR, ezrin; SPARC, secreted protein, acidic, cysteinerich (osteonectin); CTNNB1, catenin beta-1; ZEB1, zinc finger E-box binding homeobox 1; PTEN, phosphatase and tensin homolog; VIM, Vimentin. Bold text indicates statistical significance.

\section{Discussion}

WWOX is a tumor suppressor gene; its differential expression, protein presence, and elevation have been proven in previous research to be connected with better prognosis and survival in various types of cancer, such as gastric (31), ovarian (32), cervical (33) and also breast cancer (21,34-36). Nonetheless, its contribution to carcinogenesis of the endometrium has not been well defined.

We evaluated the results of WWOX silencing in a normal endometrial cell line (THESC) and two EC cell lines (Ishikawa and MFE296) in relation to representative cancer-related features, such as adhesion potential, growth in soft agar and invasiveness. The endometrial phenomenon of cell-motility changes is fundamental for many physiological processes, including implantation, embryogenesis, immune responses, wound healing, as well as the pathology of endometriosis, tumor invasion and metastasis (37). Thus, the examination of this process, concentrating on WWOX, which is the global gene expression modulator, is rational. The motility mechanism depends on the interactions of integrins with ECM proteins and the differential expression of extracellular proteins $(38,39)$. We observed as a result of WWOX silencing significant changes in adhesion potential in all examined cell lines. In the noncancerous endometrial THESC cells, a reduction of adhesion to fibronectin, collagen 1, laminin 1 and fibrinogen was noted; different effects were noted in the EC cell lines, and increased adhesion to fibronectin and fibrinogen was noted in the MFE29 cells, and increased adhesion to fibronectin in the Ishikawa cells. Our observations, showing that WWOX modulates adhesion to fibronectin are consistent with previous findings from research using ovarian and breast cancer cell lines (40-42); in these studies, WWOX restoration resulted in decreased attachment to this ECM component, which has been linked to peritoneal metastasis. The association between WWOX signaling and fibrinogen in cell-ECM interaction therefore seems to be an important feature in promoting cancer cell survival (43).

Integrins, the molecules which are essential for processes of cellular adhesion, differentiation and motility, interact from the cell side with ECM proteins. In the endometrium, the expression of $\alpha 1, \alpha 4, \alpha v$ and $\beta 3$ integrin molecules are observed periodically during the menstrual cycle (44).

The data of the present study showed that in the moderately differentiated MFE296 cell line, ectopically silenced WWOX meant higher expression of the $\alpha 3$ subunit of integrin, while in the well-differentiated Ishikawa cell line lower levels of $\alpha 1$ and $\alpha 4$ expression were observed after WWOX knockdown.

The involvement of the $\alpha 4$ integrin in tumor progression and metastasis has been previously demonstrated in different tumor types. Several authors have demonstrated that integrin $\alpha 4$ is also essential for angiogenesis $(45,46)$. As reported by Jin et al, integrin $\alpha 4$ is required for recruitment of circulating progenitor cells and circulating mononuclear cells to the site of neovascularization. Moreover, this integrin participates in interaction between the progenitor cell and the tumor endothelium (47). Also, Garmy-Susini et al stated that the $\alpha 4 \beta 1$ integrin complex facilitates the intercellular adhesion and survival of endothelial cells and pericytes during blood vessel formation (48). However, as the Ishikawa cell line is a well-differentiated one, WWOX silencing and the resulting downregulation of the $\alpha 4$ integrin subunit, which were noted in the present study, may be part of a loss of differentiated features, leading to further phenotype changes. This hypothesis is partially confirmed by studies on EC biology, which have demonstrated the role which integrin differentiation plays in relation to tumor invasiveness. As demonstrated by Prifti et al, integrin dimers $\alpha 4 \beta 1, \alpha 5 \beta 1$ and $\alpha 6 \beta 1$ are formed in a number of EC cell lines, including the Ishikawa cell line, and they are involved in processes associated with cellular adhesion (49). Moreover, a study by Lessey et al revealed an inverse correlation between the types and differential dimerization of integrins and the histological grade of the tumor, suggesting that EC cells lose certain specific integrins while gaining a more undifferentiated morphology, and consequently a metastatic phenotype. Namely, they noted that the expression of $\alpha 6$ was decreased in the lowest number of tumors of the endometrium, while $\alpha 3$ was found to be the subunit with the most frequently declining expression level in EC (50). On the other hand, Gourley et al demonstrated that WWOX 
modulates cell-ECM interaction by lowering the expression of integrin $\alpha 3$ and fibronectin (41). We noted such effects in MFE296 cells, where downregulation of WWOX resulted in the increased expression of the integrin $\alpha 3$ subunit and a strong tendency to increased adhesion of fibronectin.

Another aspect of cancer cells modulated by $W W O X$ and examined in the present study was invasiveness. We studied the invasion through a basement membrane assay and assessed MMP-2 expression.

We observed in the MFE296 cell line (with silenced $W W O X)$ a reduction in MMP-2 activity and invasion through the basement membrane. Furthermore, in these cells we also noted increased growth ability in suspension. Our results are consistent with the assumption that $W W O X$ expression raises motility potential, with a concurrent reduction in the malignant features of cancer cells. In colon, breast and EC cell lines the overexpression of $W W O X$ resulted in an increased invasiveness but reduced ability to grow in soft agar $(26,29,51)$.

On the other hand, we observed in the present study that in the well-differentiated Ishikawa cell line, silencing of the WWOX gene resulted in an increased ratio of proliferation without mobility and anchorage-independent growth changes. Similar results have also been observed in the non-cancerous/normal breast cell line MCF10 (8).

The ability of cells to invade and metastasize is the result of changes in the expression of genes modulating cell-cell, cell-matrix interactions and signal transduction $(38,52)$. In the present study, we revealed that $W W O X$ differentially modulates the expression of genes involved in cancer progression. We observed that $W W O X$ silencing resulted in increased expression of EZR, CDH1 and SPARC in the undifferentiated MFE296 cell line.

The SPARC gene can act both as an oncogene and a tumor suppressor gene depending on the cancer type (53). Yusuf et al reported that SPARC gene expression was present in poorly differentiated endometrioid adenocarcinoma tissues but not in normal endometrial tissues; furthermore, it was also noted that overexpression of the SPARC gene reinforces the expression of the EMT protein fibronectin and increased migration activity (54).

Thus, increased expression of SPARC as a probable result of downregulation of $W W O X$ expression reinforces the hypothesis that $W W O X$ silencing during cancer progression is involved in the regulation of EMT.

Moreover, in MFE296/shWWOX cells we also noticed increased expression of the $C D H 1$ gene, which is involved in the cell-cell junction and is an important epithelial marker which is suppressed during EMT.

This adverse correlation between $W W O X$ and $C D H 1$ was observed in our previous epidemiological EC study, but the correlation was noted in relation to the other well-differentiated EC cell line ECC1 $(22,29)$.

In the present study, both in the well- and moderately differentiated cell lines, negative correlation was noted between the $W W O X$ and $E Z R$ gene associated with anchoring actin to the cell membrane. Increased expression of $E Z R$ is connected with reduced overall survival in FIGO stage I (55) and is an essential driver of metastatic potential in EC (56).

In conclusion, the results of our present study strongly suggest that the $W W O X$ gene is involved in the process of endometrial carcinogenesis. Our observations demonstrate that the $W W O X$ gene modulates the adhesion process in healthy endometrial cells as well as in tumor cells of varying differentiation. Moreover, we suggest that in the moderately differentiated EC cell line, MFE296, the WWOX gene, despite increasing the motility of cells, exerts a tumor-suppressing function by inhibiting growth. In addition, in this type of cell, we suggest that $W W O X$ is involved in regulation of $C D H 1$, EZR and SPARC pathways.

However, its influence appears to depend on the stage of carcinogenesis, but further studies should be conducted in order to better understand the complexity of the functioning of the $W W O X$ gene.

\section{Acknowledgements}

This study was funded by the National Center of Sciences N N407 168940.

\section{References}

1. Ministry of Health; National Cancer Registry of Poland: Reports based on data of National Cancer Registry of Poland (updated 19-11-2010). http://epid.coi.waw.pl/krn/english/index.asp. Accessed June 30, 2012.

2. Bokhman JV: Two pathogenetic types of endometrial carcinoma. Gynecol Oncol 15: 10-17, 1983.

3. Doll A, Abal M, Rigau M, Monge M, Gonzalez M, Demajo S, Colás E, Llauradó M, Alazzouzi H, Planagumá J, et al: Novel molecular profiles of endometrial cancer-new light through old windows. J Steroid Biochem Mol Biol 108: 221-229, 2008.

4. Ryan AJ, Susil B, Jobling TW and Oehler MK: Endometrial cancer. Cell Tissue Res 322: 53-61, 2005.

5. O'Hara AJ and Bell DW: The genomics and genetics of endometrial cancer. Adv Genomics Genet 2012: 33-47, 2012.

6. Okuda T, Sekizawa A, Purwosunu Y, Nagatsuka M, Morioka M, Hayashi M and Okai T: Genetics of endometrial cancers. Obstet Gynecol Int 2010: 984013, 2010.

7. Merritt MA and Cramer DW: Molecular pathogenesis of endometrial and ovarian cancer. Cancer Biomark 9: 287-305, 2010.

8. Ferguson BW, Gao X, Zelazowski MJ, Lee J, Jeter CR, Abba MC and Aldaz CM: The cancer gene WWOX behaves as an inhibitor of SMAD3 transcriptional activity via direct binding. BMC Cancer 13: 593, 2013.

9. Kurek KC, Del Mare S, Salah Z, Abdeen S, Sadiq H, Lee SH, Gaudio E, Zanesi N, Jones KB, DeYoung B, et al: Frequent attenuation of the WWOX tumor suppressor in osteosarcoma is associated with increased tumorigenicity and aberrant RUNX2 expression. Cancer Res 70: 5577-5586, 2010.

10. Gaudio E, Palamarchuk A, Palumbo T, Trapasso F, Pekarsky Y, Croce CM and Aqeilan RI: Physical association with WWOX suppresses c-Jun transcriptional activity. Cancer Res 66: 11585-11589, 2006.

11. Aqeilan RI, Pekarsky Y, Herrero JJ, Palamarchuk A, Letofsky J, Druck T, Trapasso F, Han SY, Melino G, Huebner K, et al: Functional association between Wwox tumor suppressor protein and p73, a p53 homolog. Proc Natl Acad Sci USA 101: 4401-4406, 2004.

12. Aqeilan RI, Palamarchuk A, Weigel RJ, Herrero JJ, Pekarsky Y and Croce CM: Physical and functional interactions between the Wwox tumor suppressor protein and the AP-2gamma transcription factor. Cancer Res 64: 8256-8261, 2004.

13. Aqeilan RI, Donati V, Palamarchuk A, Trapasso F, Kaou M, Pekarsky Y, Sudol M and Croce CM: WW domain-containing proteins, WWOX and YAP, compete for interaction with ErbB-4 and modulate its transcriptional function. Cancer Res 65: 6764-6772, 2005.

14. Aqeilan RI, Donati V, Gaudio E, Nicoloso MS, Sundvall M, Korhonen A, Lundin J, Isola J, Sudol M, Joensuu H, et al: Association of Wwox with ErbB4 in breast cancer. Cancer Res 67: 9330-9336, 2007.

15. Abu-Remaileh M and Aqeilan RI: Tumor suppressor WWOX regulates glucose metabolism via HIF1 $\alpha$ modulation. Cell Death Differ 21: 1805-1814, 2014. 
16. Aqeilan RI and Croce CM: WWOX in biological control and tumorigenesis. J Cell Physiol 212: 307-310, 2007.

17. Aqeilan RI, Hagan JP, de Bruin A, Rawahneh M, Salah Z, Gaudio E, Siddiqui H, Volinia S, Alder H, Lian JB, et al: Targeted ablation of the WW domain-containing oxidoreductase tumor suppressor leads to impaired steroidogenesis. Endocrinology 150: 1530-1535, 2009.

18. Bednarek AK, Laflin KJ, Daniel RL, Liao Q, Hawkins KA and Aldaz CM: WWOX, a novel WW domain-containing protein mapping to human chromosome $16 \mathrm{q} 23.3-24.1$, a region frequently affected in breast cancer. Cancer Res 60: 2140-2145, 2000.

19. Lan C, Chenggang W, Yulan B, Xiaohui D, Junhui Z and Xiao W: Aberrant expression of WWOX protein in epithelial ovarian cancer: A clinicopathologic and immunohistochemical study. Int J Gynecol Pathol 31: 125-132, 2012.

20. Qin HR, Iliopoulos D, Nakamura T, Costinean S, Volinia S, Druck T, Sun J, Okumura H and Huebner K: Wwox suppresses prostate cancer cell growth through modulation of ErbB2-mediated androgen receptor signaling. Mol Cancer Res 5: 957-965, 2007.

21. Płuciennik E, Kusińska R, Potemski P, Kubiak R, Kordek R and Bednarek AK: WWOX--the FRA16D cancer gene: Expression correlation with breast cancer progression and prognosis. Eur J Surg Oncol 32: 153-157, 2006

22. Płuciennik E, Kośla K, Wójcik-Krowiranda K, Bieńkiewicz A and Bednarek AK: The WWOX tumor suppressor gene in endometrial adenocarcinoma. Int J Mol Med 32: 1458-1464, 2013

23. Cui Z, Lin D, Cheng F, Luo L, Kong L, Xu J, Hu J and Lan F: The role of the WWOX gene in leukemia and its mechanisms of action. Oncol Rep 29: 2154-2162, 2013

24. Ishii H, Vecchione A, Furukawa Y, Sutheesophon K, Han SY, Druck T, Kuroki T, Trapasso F, Nishimura M, Saito Y, et al: Expression of FRA16D/WWOX and FRA3B/FHIT genes in hematopoietic malignancies. Mol Cancer Res 1: 940-947, 2003.

25. Liu SY, Chiang MF and Chen YJ: Role of WW domain proteins WWOX in development, prognosis, and treatment response of glioma. Exp Biol Med (Maywood) 240: 315-323, 2015.

26. Nowakowska M, Pospiech K, Lewandowska U, PiastowskaCiesielska AW and Bednarek AK: Diverse effect of WWOX overexpression in HT29 and SW480 colon cancer cell lines. Tumour Biol 35: 9291-9301, 2014.

27. Xie B, Zen Q, Wang X, He X, Xie Y, Zhang Z and Li H: ACK1 promotes hepatocellular carcinoma progression via downregulating WWOX and activating AKT signaling. Int J Oncol 46: 2057-2066, 2015

28. Yan H and Sun Y: Evaluation of the mechanism of epithelialmesenchymal transition in human ovarian cancer stem cells transfected with a WW domain-containing oxidoreductase gene. Oncol Lett 8: 426-430, 2014

29. Płuciennik E, Nowakowska M, Pospiech K, Stępień A Wołkowicz M, Gałdyszyńska M, Popeda M, WójcikKrowiranda K, Bieńkiewicz A and Bednarek AK: The role of WWOX tumor suppressor gene in the regulation of EMT process via regulation of CDH1-ZEB1-VIM expression in endometrial cancer. Int J Oncol 46: 2639-2648, 2015.

30. Pfaffl MW, Horgan GW and Dempfle L: Relative expression software tool (REST) for group-wise comparison and statistical analysis of relative expression results in real-time PCR. Nucleic Acids Res 30: e36, 2002.

31. Aqeilan RI, Kuroki T, Pekarsky Y, Albagha O, Trapasso F, Baffa R, Huebner K, Edmonds P and Croce CM: Loss of WWOX expression in gastric carcinoma. Clin Cancer Res 10: 3053-3058, 2004.

32. Nunez MI, Rosen DG, Ludes-Meyers JH, Abba MC, Kil H, Page R, Klein-Szanto AJ, Godwin AK, Liu J, Mills GB, et al: WWOX protein expression varies among ovarian carcinoma histotypes and correlates with less favorable outcome. BMC Cancer 5: 64, 2005.

33. Qu J, Lu W, Li B, Lu C and Wan X: WWOX induces apoptosis and inhibits proliferation in cervical cancer and cell lines. Int J Mol Med 31: 1139-1147, 2013.

34. Bednarek AK, Keck-Waggoner CL, Daniel RL, Laflin KJ, Bergsagel PL, Kiguchi K, Brenner AJ and Aldaz CM: WWOX, the FRA16D gene, behaves as a suppressor of tumor growth. Cancer Res 61: 8068-8073, 2001

35. Nunez MI, Ludes-Meyers J, Abba MC, Kil H, Abbey NW, Page RE, Sahin A, Klein-Szanto AJ and Aldaz CM: Frequent loss of WWOX expression in breast cancer: Correlation with estrogen receptor status. Breast Cancer Res Treat 89: 99-105, 2005.
36. Göthlin Eremo A, Wegman P, Stål O, Nordenskjöld B, Fornander $\mathrm{T}$ and Wingren S: Wwox expression may predict benefit from adjuvant tamoxifen in randomized breast cancer patients. Oncol Rep 29: 1467-1474, 2013.

37. Schwenke M, Knöfler M, Velicky P, Weimar CH, Kruse M, Samalecos A, Wolf A, Macklon NS, Bamberger AM and Gellersen B: Control of human endometrial stromal cell motility by PDGF-BB, HB-EGF and trophoblast-secreted factors. PLoS One 8: e54336, 2013

38. Desgrosellier JS and Cheresh DA: Integrins in cancer: biological implications and therapeutic opportunities. Nat Rev Cancer 10: 9-22, 2010

39. Li X, Regezi J, Ross FP, Blystone S, Ilić D, Leong SP and Ramos DM: Integrin alphavbeta3 mediates K1735 murine melanoma cell motility in vivo and in vitro. J Cell Sci 114: 2665-2672, 2001

40. Abdeen SK, Salah Z, Khawaled S and Aqeilan RI: Characterization of WWOX inactivation in murine mammary gland development. J Cell Physiol 228: 1391-1396, 2013.

41. Gourley C, Paige AJ, Taylor KJ, Ward C, Kuske B, Zhang J, Sun M, Janczar S, Harrison DJ, Muir M, et al: WWOX gene expression abolishes ovarian cancer tumorigenicity in vivo and decreases attachment to fibronectin via integrin $\alpha 3$. Cancer Res 69: 4835-4842, 2009.

42. Zhang JQ, Li L, Song HL, Paige A and Gabra H: Effect of WWOX gene on the attachment and adhesion of ovarian cancer cells. Zhonghua Fu Chan Ke Za Zhi 44: 529-532, 2009 (In Chinese).

43. Palumbo JS and Degen JL: Fibrinogen and tumor cell metastasis. Haemostasis 31 (Suppl 1): S11-S15, 2001.

44. Lessey BA, Castelbaum AJ, Buck CA, Lei Y, Yowell CW and Sun J: Further characterization of endometrial integrins during the menstrual cycle and in pregnancy. Fertil Steril 62: 497-506, 1994.

45. Rebhun RB, Cheng H, Gershenwald JE, Fan D, Fidler IJ and Langley RR: Constitutive expression of the alpha4 integrin correlates with tumorigenicity and lymph node metastasis of the B16 murine melanoma. Neoplasia 12: 173-182, 2010.

46. Holzmann B1, Gosslar U and Bittner M: Alpha 4 integrins and tumor metastasis. Curr Top Microbiol Immunol 231: 125-141, 1998.

47. Jin H, Aiyer A, Su J, Borgstrom P, Stupack D, Friedlander M and Varner J: A homing mechanism for bone marrow-derived progenitor cell recruitment to the neovasculature. J Clin Invest 116: 652-662, 2006.

48. Garmy-Susini B, Jin H, Zhu Y, Sung RJ, Hwang R and Varner J: Integrin $\alpha 4 \beta 1$-VCAM-1-mediated adhesion between endothelial and mural cells is required for blood vessel maturation. J Clin Invest 115: 1542-1551, 2005.

49. Prifti S, Zourab Y, Koumouridis A, Bohlmann M, Strowitzki T and Rabe T: Role of integrins in invasion of endometrial cancer cell lines. Gynecol Oncol 84: 12-20, 2002.

50. Lessey BA, Albelda S, Buck CA, Castelbaum AJ, Yeh I, Kohler M and Berchuck A: Distribution of integrin cell adhesion molecules in endometrial cancer. Am J Pathol 146: 717-726, 1995.

51. Lewandowska U, Żelazowski M, Seta K, Byczewska M, Płuciennik E and Bednarek AK: WWOX, the tumour suppressor gene affected in multiple cancer. J Physiol Pharmacol 60 (Suppl 1): 47-56, 2009

52. Martin TA and Jiang WG: Loss of tight junction barrier function and its role in cancer metastasis. Biochim Biophys Acta 1788: 872-891, 2009

53. Neuzillet C, Tijeras-Raballand A, Cros J, Faivre S, Hammel P and Raymond E: Stromal expression of SPARC in pancreatic adenocarcinoma. Cancer Metastasis Rev 32: 585-602, 2013.

54. Yusuf N, Inagaki T, Kusunoki S, Okabe H, Yamada I, Matsumoto A, Terao Y, Takeda S and Kato K: SPARC was overexpressed in human endometrial cancer stem-like cells and promoted migration activity. Gynecol Oncol 134: 356-363, 2014.

55. Köbel M, Langhammer T, Hüttelmaier S, Schmitt WD, Kriese K, Dittmer J, Strauss HG, Thomssen C and Hauptmann S: Ezrin expression is related to poor prognosis in FIGO stage I endometrioid carcinomas. Mod Pathol 19: 581-587, 2006.

56. Ohtani K, Sakamoto H, Rutherford T, Chen Z, Kikuchi A, Yamamoto T, Satoh K and Naftolin F: Ezrin, a membranecytoskeletal linking protein, is highly expressed in atypical endometrial hyperplasia and uterine endometrioid adenocarcinoma. Cancer Lett 179: 79-86, 2002. 